\title{
Price pressures on metals
}

\author{
Precious metals are an integral part of chemistry and the modern economy. Given their high and volatile prices, \\ alternatives must be sought.
}

( eveloping catalysts using low cost, readily available materials instead of precious (generally platinum group) metals has been a trend in chemistry for some time. Within synthetic chemistry, both academia and industry are focusing more on base metals, organocatalysts and increasingly, enzymes, in place of the once ubiquitous precious metal catalysts. Heterogeneous catalysis and electrocatalysis are moving in a similar direction, with increasing steps to reduce or eliminate the use of these metals in processes from $\mathrm{CO}$ oxidation to fuel cells.

It can be assumed that price is a major factor driving this desire to switch from precious metals. And with the current global economic uncertainty, market forces tend to push the cost of some of these metals higher. Silver, and especially gold, can be seen as safe investments and a hedge against inflation when returns on other stocks, shares and bonds are lower. This explains why gold is at a high not seen since the height of the global financial crisis, when it reached values close to US\$60 per gram (at the time of writing, it sits around US $\$ 49$ per gram - still well above its historical average $)^{1}$.

The platinum group metals are less likely to be used as investments, and changes in these prices are more often due to variations in output or consumer demand. Lower volume metals tend to display much higher volatility, with even small variations in supply or demand leading to sudden price spikes or crashes. Iridium is a case in point - it has more than doubled in price over the last three years (US $\$ 47$ per gram at the time of writing). Uses in industrial catalysts are likely one factor driving this increase - think, for example, of the Cativa process for production of acetic acid, or the use of iridium oxides in the chloralkali process. And given its scarcity, even low levels of increased usage would be quickly reflected in the market price. Rhodium has also seen step price increases in recent years (up to US $\$ 129$ per gram, more than four times its value in 2017), presumably for similar reasons.

High metal prices cause pain for producers and consumers alike, especially when you consider the role of catalysis in so many day-to-day necessities, from pharmaceuticals to transport. However, in the longer term it can be a driving force for the development of new technologies. Catalysts with activities that rival (or outperform) those of the prior state-ofthe-art platinum group metals are being developed all the time. Without high and volatile prices, the incentive to research in this area would have been reduced. Similarly, high metal prices also necessitate the development of approaches to recover and recycle metals deployed in current goods and consumables, with the effect of promoting sustainable consumption and production.

\section{"High metal prices cause pain for producers and consumers alike, especially when you consider the role of catalysis in so many day- to-day necessities, from pharmaceuticals to transport."}

It seems clear that increased prices can drive innovation in alternative technologies.
But what about the reverse process? Would a drop in metal price lead to the development of new uses for that metal? Take platinum as a case in point: recently, it looked as though it would experience a price drop $^{2}$. Production was high, but the likely increasing market share of electric vehicles meant that the demand from the automobile industry was likely to soften, and so prices remained subdued. In part to take advantage of the surplus platinum, and to create additional demand to compensate for lower demand in catalytic converters, producers supported research on developing new lithium-oxygen and lithium-sulfur batteries that would use platinum and palladium ${ }^{3}$. The quick response to market changes is striking. (Note, however, that the market outlook ${ }^{4}$ has recently fluctuated somewhat, and surpluses are now expected to be much lower).

Chemistry and economics are inextricably linked, and it is true that market trends may not be the best way to plan for the future. But, in the case of metal prices, if not in others, we should be happy that the market is, in general, pushing us towards more sustainable and environmentally friendly processes.

Published online: 13 September 2019 https://doi.org/10.1038/s41929-019-0359-7

References

1. Commodity and metal prices. InfoMine https://go.nature. com/2Zy1HeJ (Accessed August 2019).

2. Hobson, P. Platinum market set for big surpluses in 2018 and 2019: WPIC. Reuters https://go.nature.com/2L3Icmz (2018).

3. Anglo American platinum and platinum group metals ltd. launch new venture to develop next generation battery technology. AngloAmerican https://go.nature.com/2PmXmrl (2019).

4. Platinum Quarterly (World Platinum Investment Council, 2019); https://go.nature.com/2ZF0d2o. 